\title{
MEDICAL CARE AT THE END \\ OF LIFE: DISEASES, TREATMENT \\ PATTERNS, AND COSTS
}

Alan M. Garber

Thomas E. MaCurdy

Mark L. McClellan

Working Paper 6748

http://www.nber.org/papers/w6748

\author{
NATIONAL BUREAU OF ECONOMIC RESEARCH \\ 1050 Massachusetts Avenue \\ Cambridge, MA 02138 \\ October 1998
}

This research was supported in part by grants AG07651, AG1 1706, and AG05842 from the National Institute on Aging, by grant 96170 from the Commonwealth Fund, and by grant 26749 from The Robert Wood Johnson Foundation. We are grateful to Victoria Stodden for excellent research assistance and to Joe Antos for helpful discussion.. The views expressed here are those of the authors and do not reflect those of the National Bureau of Economic Research.

(C) 1998 by Alan M. Garber, Thomas E. MaCurdy, and Mark C. McClellan. All rights reserved. Short sections of text, not to exceed two paragraphs, may be quoted without explicit permission provided that full credit, including $\mathbb{C}$ notice, is given to the source. 
Medical Care at the End of Life:

Diseases, Treatment Patterns, and Costs

Alan M. Garber, Thomas E. MaCurdy, and Mark C. McClellan

NBER Working Paper No. 6748

October 1998

JEL No: I12

\begin{abstract}
In recent years, the use of Medicare-covered home health care and hospice services has grown dramatically. Hospice care, like much home health and nonacute hospital care, is designed to meet the needs of dying patients, who are known to generate disproportionately large costs of care. How has use of these services by dying Medicare beneficiaries changed over time? How has it varied by disease? Does recent experience suggest that these services have helped save the Medicare program money by displacing hospital care and other costly services? To address these questions, we examined linked Medicare claims files from 1988 to 1995, determining the location of death, days of use of services, and expenditures for the care of beneficiaries in the final months of life.

We found that use of hospice and home health services by decedents grew rapidly over the eight-year study period, and especially rapidly among patients who died with a predictably terminal illness such as lung cancer. Among the elderly who have such illnesses, these alternatives to acute hospital care have reduced the use of hospital care near the very end of life. Most of the growth in these services in the year or two before death, however, appears to involve additional Medicarecovered services. As a result, utilization of Medicare-covered home health and hospice care by dying beneficiaries has increased over time, with an associated reduction in the proportion of deaths occurring in acute-care hospitals. But as the use of non-hospital services has grown, the growth in Medicare expenditures for hospital services at the end of life has not slowed appreciably, nor has there been a marked change in the intensity of end-of-life treatment for Medicare beneficiaries dying of more acute illnesses or requiring substantial supportive care.
\end{abstract}

Alan M. Garber

NBER

30 Alta Road

Stanford, CA 94305-8006

garber@stanford.edu

Mark C. McClellan

NBER

30 Alta Road

Stanford, CA 94305-8006

markmc@texas.stanford.edu
Thomas E. MaCurdy

NBER

30 Alta Road

Stanford, CA 94305-8006

tmac@leland.stanford.edu 


\section{Introduction}

Discussions of the high level and rate of growth of Medicare expenditures often focus on expenditures for the care of beneficiaries who are nearing the end of life. Medicare recipients typically use medical services heavily as the time of death nears: historically, Medicare recipients in their final year of life generated about six times the expenditures of the average surviving Medicare enrollee and accounted for almost 30 percent of total program spending (Lubitz and Riley 1993). The use of health care accelerates rapidly during the final months of life, leading many observers to infer that some of the care provided is futile and might be avoided or replaced by more appropriate end-of-life care (Bayer, Callahan et al. 1983; Lubitz and Prihoda 1984;

Scitovsky 1984; Scitovsky 1988; Lubitz and Riley 1993; Schneiderman and Jecker 1993; Emanuel and Emanuel 1994; Scitovsky 1994).

When a patient's illness is expected to end in death, the goals of health care can be shifted away from prolonging life-via aggressive, expensive, and sometimes painful interventions such as major operations and intensive care-toward comfort and relief of suffering. The hallmarks of care targeted to the needs of dying patients include de-emphasis or elimination of the intensive treatments that accompany acute hospitalization, and an emphasis on pain control and other measures to improve the quality of the final stage of life. Such care is offered by both inpatient and outpatient hospice, and is often a feature of home health services. Hospice and home health care became more popular during the past decade, as Medicare benefits for these services became more widely available.

Home health care, in particular, was used more widely for the elderly who were severely ill, along with those who had more limited acute or subacute health problems. The home health benefit was intended to obviate or diminish the need for hospitalization among the elderly with acute health problems, but Medicare recipients who had chronic diseases also used it heavily. Home health care received after acute hospitalization has been eligible for reimbursement since the beginning of the Medicare program, but two key developments in Medicare reimbursement have led to its much more widespread use today.

The first was the implementation of the Prospective Payment System (PPS) for hospitalizations in 1984. Under PPS, hospitals received fixed payments per hospital admission, adjusted for the diagnosis-related group (DRG) that characterized the admission. Since prolongation of a hospital stay raised the hospital's costs but not its revenues, PPS made it more 
attractive for hospitals to use alternatives to hospitalization, such as home health care, for their patients who did not need the full range of acute hospital services but were not well enough to return home. Because home care was not considered a cost of hospitalization covered under the fixed per-case reimbursement, hospitals gained financially when they discharged patients to home care rather than prolonging their hospital stays.

A second change was implemented in 1989 , in the wake of a 1988 Federal district court decision (Duggan vs. Bowen) that the Health Care Financing Administration's interpretation of the home health benefit had been too restrictive. The revised Medicare Home Health Agency Manual clarified coverage criteria and resulted in expanded coverage (Vladeck and Miller, 1994). These regulatory changes were soon followed by rapid growth in the supply of home health services (often provided by for-profit home health agencies), and rapid growth in the use of the Medicare home health benefit. Between 1988 and 1994, the percentage of Medicare expenditures attributable to home health care rose from $2.4 \%$ to $7.9 \%$; between 1989 and 1992 , the number of visits per beneficiary nearly doubled, from 27 to 53 (Vladeck and Miller, 1994). Alleged abuses of the home health benefit led the Office of the Inspector General of the Department of Health and Human Services to audit home health care and issue regulations designed to detect and deter fraud and abuse.

The principal cause of this growth, according to some observers, is the absence of disincentives to use home health care: home health services are now essentially free to beneficiaries. But it is possible that growth in the use of home health care has had offsetting effects on the use of inpatient hospital services. Because their functional status often declines as part of the illnesses preceding death, Medicare beneficiaries near death may be particularly affected by the home health care expansions. In particular, if patients have been better able to make use of these services, in place of acute hospital services that are also likely to be "free" to them, Medicare expenditure growth near death may have moderated as a result. Thus the policy change may have supported an important shift in nature and cost of health care for the dying.

The relatively broad coverage of home health services contrasts with stricter regulation of hospice care. Medicare rules state that a beneficiary may become eligible for hospice care, which is generally delivered in the home, when his or her life expectancy falls to 6 or fewer months. Since 1992, hospice care has been subject to stricter determinations of reimbursement eligibility than home health care, although reimbursement rates for hospice care are generally higher. One reason for this greater regulatory rigor may be the apparently objective nature of the limit on the 
benefit: instead of a potentially nebulous coverage rule, such as "all necessary services," hospice coverage is time-based. Life expectancy is not the same as actual length of life. But if payment is often challenged for patients receiving care for much longer than six months, then physicians and hospices might be reluctant to enroll patients in hospice until near the very end of life. Of course, many hospice services can be provided under the home health benefit, so providers can avoid such regulatory challenges, but less favorable reimbursement might be a strong deterrent to substitution of home health for hospice care.

In this chapter, we explore the consequences of these changes in Medicare utilization for care near the end of life. How have expanded hospice and home health benefits altered end-oflife care for Medicare recipients? We examine patterns of utilization of Medicare-financed services in various periods before death, both for Medicare decedents generally and for those who have specific common diseases, such as cancers and acute myocardial infarction (heart attack). We seek to learn whether Medicare recipients who died in the 1990s used home health care and hospice services more heavily than earlier cohorts of decedents, and whether the growth in use of home health care services was greater among decedents than among surviving Medicare recipients. We examine both the location of death and the number of days that these services were used during various periods before death. We discuss whether increases in such services substituted for hospital care, or whether these enhanced services simply added to the total utilization of Medicare-covered services. Our analyses draw on comprehensive data for a large random sample of Medicare recipients.

\section{Data}

We compiled longitudinal summary data from all Medicare claims for a $20 \%$ random sample of Medicare beneficiaries from 1988 through 1995. We excluded Medicare recipients less than 65 years of age or more than 99 years of age, those who resided outside the United States, and those who were enrolled in health maintenance organizations (primarily under capitated agreements). We excluded Medicare "risk" enrollees because detailed claims information was not available for them. Because they comprised a small fraction of all enrollees during the period of study, their exclusion appears to have had little effect on our results.

The resulting analytic sample consisted of almost 300,000 elderly decedents for each of the eight years. We measured their utilization of the following specific categories of services: acute care hospital; home health care; nonacute care hospital; outpatient hospital services; home 
hospice; inpatient hospice. We also measured Medicare expenditures, including both acute and nonacute Medicare-covered hospital admissions and hospice care (all covered under Part A, Medicare's hospital benefit program) and home health expenditures (mainly covered under Part A), as well as outpatient hospital care, physician services, and other supplies (all covered under Part B, the component of Medicare largely responsible for outpatient services). ${ }^{1}$ We considered two principal measures of each of these types of expenditures: actual Medicare program expenditures (Medicare reimbursement) for the care of beneficiaries, and total expenditures for these services, inclusive of patient payments. Thus total expenditures included the beneficiary's liabilities due to copayments, deductibles, and maximum limits on Medicare payments.

Expenditures for services not covered by Medicare at all, such as outpatient prescription drugs, were not included. ${ }^{2}$ For the most part, beneficiary payments (copayments and deductibles) tracked Medicare reimbursements closely. In the results presented here, we focus primarily on Medicare program payments; results for total reimbursement and patient payments were similar.

To calculate expenditures for specific periods of time, we added together Medicare expenditures for all valid claims during the period in question. We converted all costs into 1995 dollars using the gross domestic product (GDP) deflator.

We also sought to determine which kinds of services Medicare recipients were using at the time of their deaths. Many decedents died in a readily identifiable location. The location might have been revealed, for example, by a date of death corresponding to the discharge date from an acute or nonacute care hospital or nursing home, or the end date for an outpatient service such as outpatient hospice or home health care. If no other claims identifying a precise location of death were available but a patient was receiving hospice or home health care in the last 30 days of life, we assigned the patient's location of death accordingly. If no claims were recorded during the final month of life, the beneficiary was assumed to have died at home without services, or in a long-term care facility not covered by Medicare.

1

We integrated information from the five major administrative data files maintained by the Health Care Financing Administration: claims for hospital and skilled nursing facility stays (MEDPAR, or Medical Provider Analysis and Review files), home health care (HHA, or Home Health Agency), hospice care, outpatient visits, and physician and supplier services.

The other major type of uncovered service is long-term stays in nursing homes. Nursing home admissions after an acute-care admission are covered for the first hundred days, so that the vast majority of shorter nonacute hospital stays for the elderly are now covered by Medicare. 
Because we expected trends to vary with the underlying disease or cause of death, we assigned to each decedent a disease category, based on the 72-category diagnostic classification developed by the National Center for Health Statistics for reporting mortality information. We assigned diagnoses based on the inpatient (from the MEDPAR files) or outpatient diagnoses preceding death; claims for such services existed for about $60 \%$ of decedents. The disease is classified according to the primary diagnosis recorded during the last year of life that accounted for the largest share of beneficiary spending. This diagnosis is likely to be the health condition responsible for the most utilization during the final year of life.

Before performing our analyses, we carried out simple tests to determine whether our Medicare sample was representative of elderly American decedents generally. We compared ageadjusted mortality rates for the U.S. Vital Statistics series as compiled by the National Center for Health Statistics with rates that we calculated from the Medicare files. Discrepancies could arise primarily from omissions of deaths or coding errors. We found that the age-adjusted mortality rates were nearly identical.

Furthermore, the demographic characteristics of decedents were essentially the same in both sources of data: $7 \%-8 \%$ of decedents were men 65 to 74 years of age, $16 \%-17 \%$ were men 75 to 84 years of age, and $35 \%$ were men 85 or more years of age. Women 65 to 74 years of age accounted for $4 \%$ of deaths, those at age 75 to 84 accounted for $10 \%$ of deaths, and those 85 and more years of age accounted for $28 \%$ of deaths, in both data sets in 1988 . These proportions remained relatively constant through 1995 .

\section{Results}

Our results indicate that the growth in utilization of non-hospital services among decedents was significant, whether measured by changes in the location of death, days of use of the services, or expenditures.

\section{Location of Death}

Most beneficiaries use Medicare-covered services shortly before they die, and these health services often define the location of death. Many Americans die in acute care hospitals, others in nursing homes, and still others without services covered by Medicare. Here we use the term "location" to include both the physical place at which the individual died and the category of

services being received. The location of a person who died while receiving no current services is 
classified as "home," although many of these beneficiaries undoubtedly died in nursing homes. Other locations are "acute care hospital," "nursing home," "home health care" (residing at home while received home health services), "nonacute care hospital," "hospital outpatient," "hospice at home," and "hospice in hospital."

Figure la shows the distribution of location of death for Medicare recipients between 1988 and 1995. During this period, the percentage of Medicare recipients who died in an acute care hospital fell from about $42 \%$ to less than $35 \%$. The percentage who died without any Medicarecovered services fell much more dramatically, from about $40 \%$ in 1988 to about $25 \%$ in 1995 . Most of the drop occurred between 1988 and 1989, but the trend continued in later years. Although rates of deaths in several other locations changed little, the percentage of enrollees dying while receiving home health care rose sharply between 1988 and 1989, from nearly none to about 6\%. Between 1989 and 1995, hospice (both inpatient and outpatient) became a much more common site of death; the fraction of decedents enrolled in hospice rose from about $2 \%$ to more than $10 \%$. Thus, growth in the use of both hospice and home health care exceeded the drop in the percentages of beneficiaries who died at home without services and of those who died during an acute care hospitalization.

\section{Disease-Specific Trends}

For patients dying of chronic or subacute diseases, death is often expected and the process of dying extends over weeks to months. Such patients have greater opportunities to use services for the dying, such as hospice and home health care. Patients who die suddenly or unexpectedly are far less likely to use such services. Acute myocardial infarction (AMI) is perhaps the most common example of an acute condition that often causes rapid death in the elderly. Although AMI can occur as a complication of an operation or illness, and although it often occurs in men and women who are known to have heart disease, the event is usually sudden and unexpected, frequently causing death soon after the initial hospital admission for treatment, if not before admission can occur. Although survivors of AMI may die much later from complications of the heart attack, the cause of death may be recorded as the complication of AMI (such as an unstable heart rhythm or weakening of the heart muscle sufficient to cause severe congestive heart failure) rather than AMI itself. Thus AMI survivors are neither typical users of hospice care nor are they particularly likely to die while receiving home health care. 
Thus the major finding shown in Figure $1 \mathrm{~b}$ - little change in the location of death for Medicare recipients who died with a diagnosis of AMI during the period of study-is unsurprising. Hemorrhagic stroke, another disorder that is often quickly fatal, displays a similar pattern (Figure 1c): about 70\% of deaths occurred in an acute care hospital. Between 1988 and 1995 there was an increase in the fraction of deaths that occurred in nonacute care hospitals. Otherwise, however, there was no discernible trend in the location of death.

In contrast, lung cancer is a prototypical terminal illness, for which the imminence if not the exact timing of death is more predictable. For individuals who have advanced disease, it is nearly always the cause of death. The predictability of death means that decisions about care prior to death can be made more deliberately, unlike those for a patient who has an acute condition. Thus lung cancer and other advanced cancers are typical of conditions that routinely lead to hospice care, affording a choice between hospitalization and alternative services that is unavailable for many other conditions. The growth in utilization of hospice care is reflected in the location of death for lung cancer patients, as shown in Figure 1d. Accompanying a decline from $52 \%$ to $36 \%$ in the fraction of lung cancer deaths that occurred in hospitals was a dramatic increase in the fraction of beneficiaries who died while receiving outpatient hospice. In 1988, only about $2 \%$ of lung cancer deaths occurred while the beneficiary was receiving hospice care; by 1995 , the fraction was $30 \%$. Between 1988 and 1989 there was a large drop, from 33\% to $17 \%$, in the fraction of lung cancer patients dying at home without services; by 1995 , only about $10 \%$ of Medicare decedents with lung cancer died without Medicare-covered services.

Chronic obstructive pulmonary disease (COPD) is a category of respiratory illness that includes chronic bronchitis, emphysema, and some forms of asthma. Its severity is highly variable, causing symptoms ranging from mildly annoying to severely disabling. Even patients whose COPD is severe enough to require oxygen supplementation and frequent hospitalizations can survive for years. Furthermore, although utilization of medical services can be heavy before death, individuals who have COPD may not suffer from the severe pain that often accompanies advanced cancer. Consequently, COPD patients may be less likely than lung cancer patients to enter a hospital or seek hospice care before death. As Figure le shows, little over $35 \%$ of COPD deaths occurred in hospitals in 1995, with no change from 1988. These data contrast with the $70 \%$ rates of hospital death for AMI and hemorrhagic stroke. Like lung cancer deaths, COPD deaths were much less likely to occur at home without services in 1995 than in 1988 . The fraction of deaths at home fell from $43 \%$ to less than $22 \%$ by 1995 , with the largest drop 
occurring in 1989. Between 1988 and 1989, the fraction of COPD patients who died while receiving home care rose from about $1 \%$ to $8 \%$; by 1995 , it reached $10 \%$. The fraction who died while receiving inpatient or outpatient hospice care or nonacute hospital care also grew, from about $3 \%$ in 1988 to more than $10 \%$ in 1995 .

\section{Trends in Utilization}

Defined on the basis of services used at the time of death, the location of death serves as a crude proxy for utilization during the month before death. We now turn to direct measures of utilization, asking two questions: how extensively did Medicare recipients use various Medicarecovered services during several time periods preceding death? What were the trends in utilization between 1988 and 1995? Figure 2 displays overall monthly utilization and trends in monthly utilization for 1 to 30 days before death, 31 to 90 days before death, 91 to 365 days before death, and 366 to 730 days before death, for each of the years of observation. The measures of utilization are days in acute hospital, nonacute hospital, intensive care/coronary care unit (ICU/CCU), and home and inpatient (hospital) hospice. As Figure 2a makes clear, the number of days on which at least one service was provided rose sharply as the date of death neared. Within the final period before death, the number of days of utilization overall increased between 1988 and 1995. There was little change in ICU/CCU days, but acute hospital days fell over time, and both hospice and nonacute hospital days increased. The trends are most evident during the month preceding death, but in the two months prior and, to a lesser extent, the entire year preceding death, it is clear that hospice and nonacute hospital services were used much more heavily in 1995 than in 1988. Between 9 and 10 of the final 30 days of life were spent either in a hospital or using one of the other services, whereas fewer than 2 of the last 30 days were spent in an ICU/CCU.

Trends in disease-specific utilization correspond closely to the trends in location of death. Utilization of services before death among patients who had AMI, the most acute of the conditions examined here, changed little over time (Figure 2b). Days of ICU/CCU care were greater than for the other diagnoses, as expected, but there was little increase in the other categories of service over time, with the exception of a small increase in use of home hospice. The number of ICU/CCU days actually declined over time for Medicare recipients with hemorrhagic stroke (Figure 2c), as did acute hospital days. For this diagnosis, overall utilization fell with time, although there was a sharp rise in nonacute hospital days in 1989 . Utilization of 
home hospice and of hospital-based hospice rose substantially between 1988 and 1995 for patients who had lung cancer, especially in the month before death (Figure 2d). Although the number of acute hospital days in the final month of life fell from about 9 in 1988 to 6 in 1995, the rise in hospice days and days of other services more than offset this decline, so that the total days of service utilization rose from about 11 to 14 between 1988 and 1995. Similar but less striking trends are evident for COPD (Figure 2e).

\section{Expenditures}

The most direct evidence of substitution of services comes from expenditure data. Utilization data do not provide direct information about the total costs of care, and it is possible that a rise in home health services, for example, can directly reduce the use of hospitalizations. Furthermore, since each home health visit is less expensive than a typical acute hospital day, a reduction in hospital days, even if accompanied by a larger rise in the number of days of home health care, may reduce overall expenditures. To understand the implications of the utilization trends for Medicare expenditures, we looked at trends in category-specific and overall Medicare expenditures for decedents. The expenditure calculations include physicians' services. Because we do not measure expenditures for services that Medicare does not cover, such as prescription drugs and extended nursing home stays (or stays in nursing homes that are not Medicarequalified), our results reflect programmatic rather than all-source medical expenditures.

As Figure 3a shows, per-decedent total expenditures in the final month of life rose from about $\$ 5,400$ in 1988 to $\$ 7,400$ in 1995 , expressed in 1995 dollars. Similar, albeit weaker trends are evident in the other periods preceding the final month. Expenditures in the final month of life for inpatient and outpatient hospice care, along with expenditures for home health care, more than doubled during the interval. Because they were the largest component of health expenditures, hospital expenditures accounted for much of the overall growth, even though they grew at a slower rate. The annual rate of growth of hospital inpatient expenditures in the final month of life was $4.7 \%$, despite the rapid growth in use of other services.

As Figure $3 \mathrm{~b}$ shows, expenditures in the final month of life for decedents who had AMI rose sharply, especially in the 1990s. Between 1988 and 1995, hospital expenditures, which accounted for most of the health care expenditures during the final month of life, rose by nearly $50 \%$ in real terms, to $\$ 10,000$. For earlier intervals before death, such as the period from 1 year to 91 days before death and from 2 years to 1 year before death, the major trend was an increase 
in utilization of outpatient services. For example, the average beneficiary who died in 1988 with AMI had \$235 in outpatient Medicare expenditures during the period from 2 years to 1 year before death. By 1995 , the comparable figure had risen to $\$ 707$.

Hemorrhagic stroke (Figure 3c) exhibits similar trends. As we saw before, most deaths from this cause occur in the hospital, as is reflected in the high and rising proportion of acute hospital expenditures in the final month of life. Unlike beneficiaries who die with AMI, decedents who have hemorrhagic stroke have modest expenditures during the interval from 2 years to 1 year before death, perhaps because hemorrhagic strokes often occurs in individuals who do not have chronic illnesses. Many patients who died from AMI, in contrast, would have received medical care for previous AMI and other symptoms of coronary artery disease for many years before they died.

Lung cancer decedents (Figure 3d) had sharply rising expenditures for nonacute hospital care and for inpatient and outpatient, hospice. Inpatient expenditures during the final month of life actually declined in real terms between 1988 and 1990 but began a gradual rise in 1990 that accelerated by 1994, despite growing expenditures for nonacute hospital care and hospice care. Expenditures for COPD decedents (Figure 3e) were generally lower in the month before death than were those for AMI and hemorrhagic stroke decedents.

Another way to appreciate trends is to compare expenditures for specific services near the time of death to expenditures for all Medicare recipients for the same services. Those ratios, as shown in Figure 4, demonstrate that relative expenditures changed little over the period of study. Hospice is a unique category because the benefit is limited to those Medicare recipients who are expected to live for no more than six months. Accurate estimation of the prognosis would imply that all hospice expenditures are in the last year of life; the actual ratio is about 14 to 1 . Relative use of outpatient care and acute hospital care has increased modestly since 1989, and the relative use of other services has remained largely flat. Thus expenditures for specific categories of services by decedents has grown at about the overall rate of growth of expenditures for these services. The evidence presented here suggests that the use of hospice and home health care did not significantly reduce expenditures on other categories of care among decedents.

\section{Conclusions}

Reflecting widespread sentiment that it should provide appropriate care for beneficiaries at the end of their lives, reinforced by cost considerations, the Medicare program has made it easier 
for seriously ill recipients to gain access to alternatives to hospital care. The policy changes, including liberalization of reimbursement practices for alternatives to hospital care, apparently had the intended effect of making such services more broadly available to dying Medicare recipients. We found that use of these services grew throughout the late 1980s and early 1990s, and that the use of hospice and similar services designed for dying patients grew most rapidly among patients whose diagnoses seem most uniformly appropriate for such care. However, most of the growth in hospice care occurred among recipients in their final one to three months of life.

The longstanding recognition that medical expenditures rise before death has fueled the speculation, and perhaps the hope, that greater availability of less-intensive care targeted toward dying patients would reduce expenditures at the end of life. For our sample of Medicare decedents, whether analyzed by specific disease or more generally, utilization of acute hospitals declined over time. The simultaneous rise in the use of hospice and other services, however, meant that the number of days that patients received Medicare-covered services rose between 1988 and 1995. Although inpatient care delivered in acute care hospitals is usually the most expensive component of health services, the net effect of these changes in utilization was an increase in monthly Medicare expenditures before death, rising from about $\$ 5,500$ in 1988 to more than $\$ 7,000$ in 1995 (in 1995 dollars). Expenditures for dying Medicare recipients are expected to rise in the coming decades as the baby boomers reach advanced ages, producing a large cohort of elderly Americans. Our results suggest that there has been no reduction in the growth of per capita expenditures at the end of life, so total expenditures will grow still more rapidly when demographic trends combine with rising per capita expenditures.

Over long periods of time, according to other studies, the fraction of Medicare expenditures attributable to Medicare recipients in the final year of life has remained stable (Lubitz and Riley, 1993). Our results suggest that the increased adoption of putative substitutes for acute hospital care, such as hospice, has not slowed the growth of Medicare expenditures. However, adoption of such services might have different effects in the future, with changes in the interpretation of the hospice and home health benefits, changes in policies and reimbursement for hospitalization, and the shift toward capitation. The growing use of such services may be a salutary trend because they improve the well-being and satisfaction of dying patients and their families, but thus far there is little evidence that they will alleviate Medicare's financial challenges. 


\section{References}

Bayer, R., D. Callahan, et al. (1983). "The care of the terminally ill: mortality and economics." New England Journal of Medicine 309: 1490-1494.

Emanuel, E. and L. Emanuel (1994). "The economics of dying: the illusion of cost savings at the end of life." New England Journal of Medicine 330(8): 540-544.

Garber, A. and V. Fuchs (1992). Health expenditures for older Americans: 1990-2040, Stanford University.

Helbing, C. (1993). "Medicare program expenditures." Health Care Financing Review 1992 Annual Supplement: 23-54.

Lubitz, J. and R. Prihoda (1984). "The use and costs of Medicare services in the last two years of life." Health Care Financing Review 5: 117-131.

Lubitz, J. and G. Riley (1993). "Trends in Medicare payments in the last year of life." New Engl J Med 328(15): 1092-96.

Schneiderman, L. and N. Jecker (1993). "Futility in practice." Arch Intern Med 153: 437-41.

Scitovsky, A. (1984). "“The high cost of dying": what do the data show?" Milbank Mem Fund Q Health Soc 62: 591-608.

Scitovsky, A. (1988). "Medical care in the last twelve months of life: the relation between age, functional status, and medical care expenditures." Milbank Q 66(4): 640-60.

Scitovsky, A. A. (1994). ""The high cost of dying" revisited." Milbank Quarterly 72(4): 561-591.

Verbrugge, L. (1984). "Longer life but worsening health? Trends in health and mortality of middle-aged and older persons." Milbank Memorial Fund Quarterly 62: 475-519.

Vladeck, B.C. and N.A. Miller (1994). "The Medicare Home Health Initiative." Health Care Financing Review 16(1):7-16. 


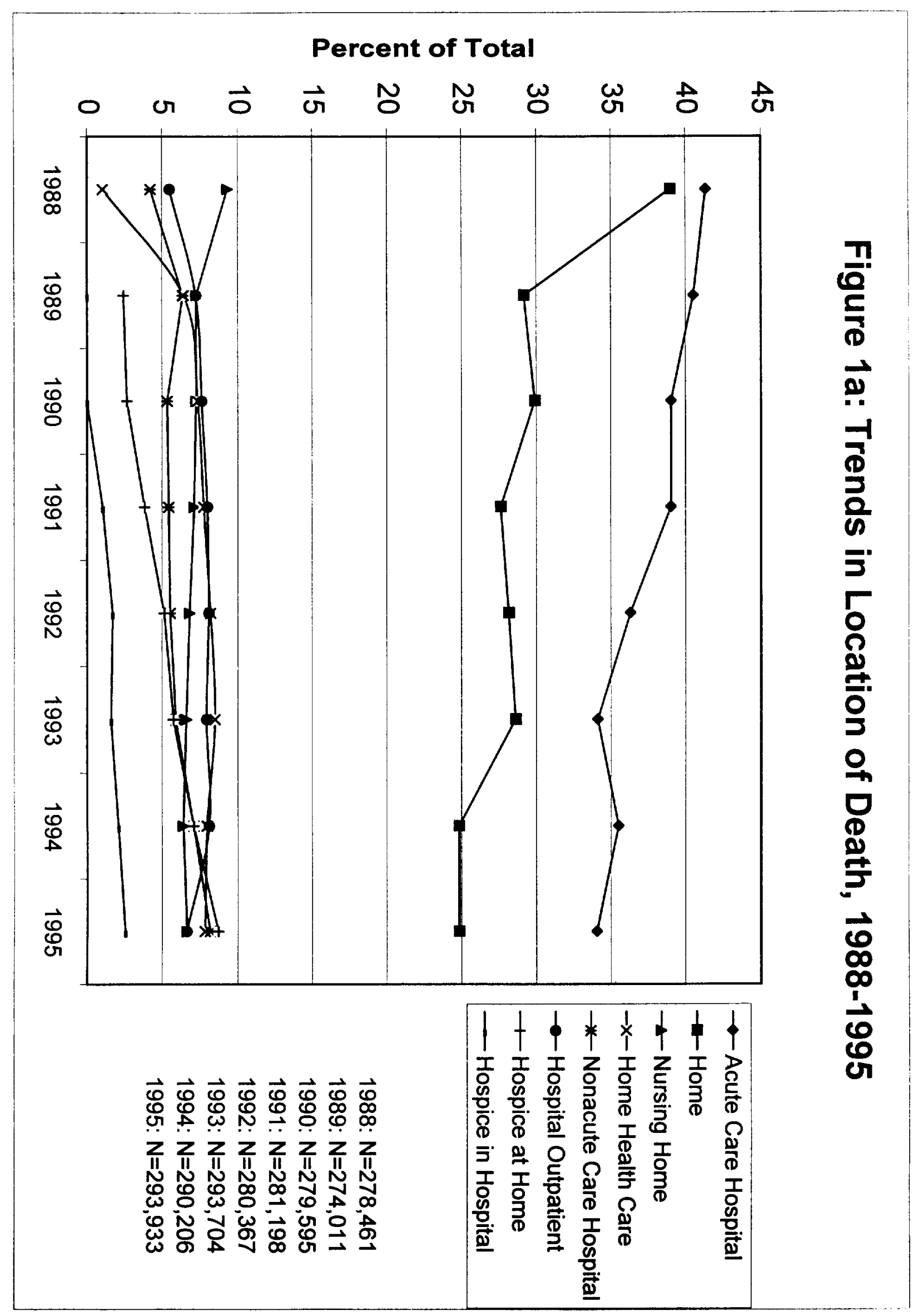




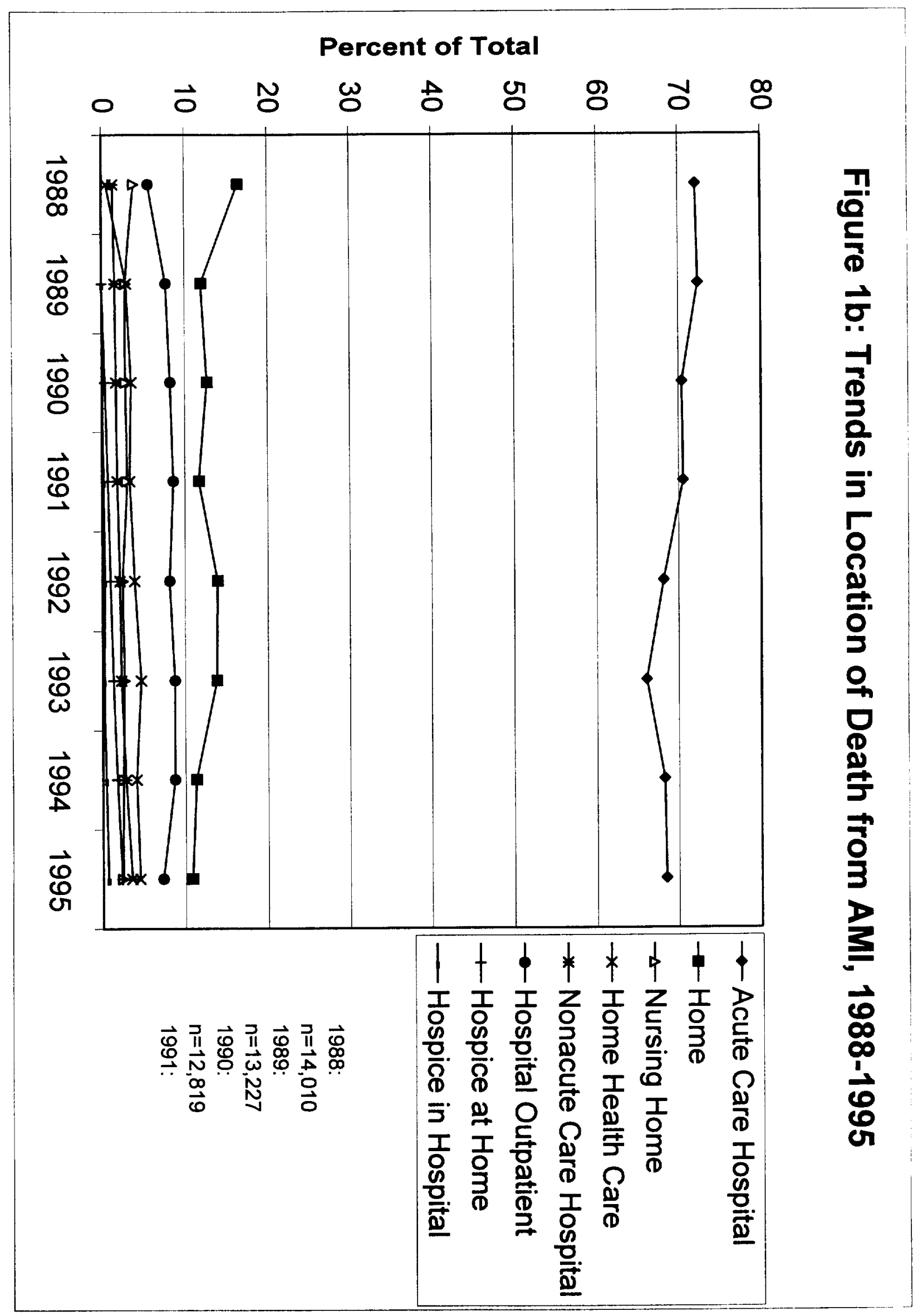




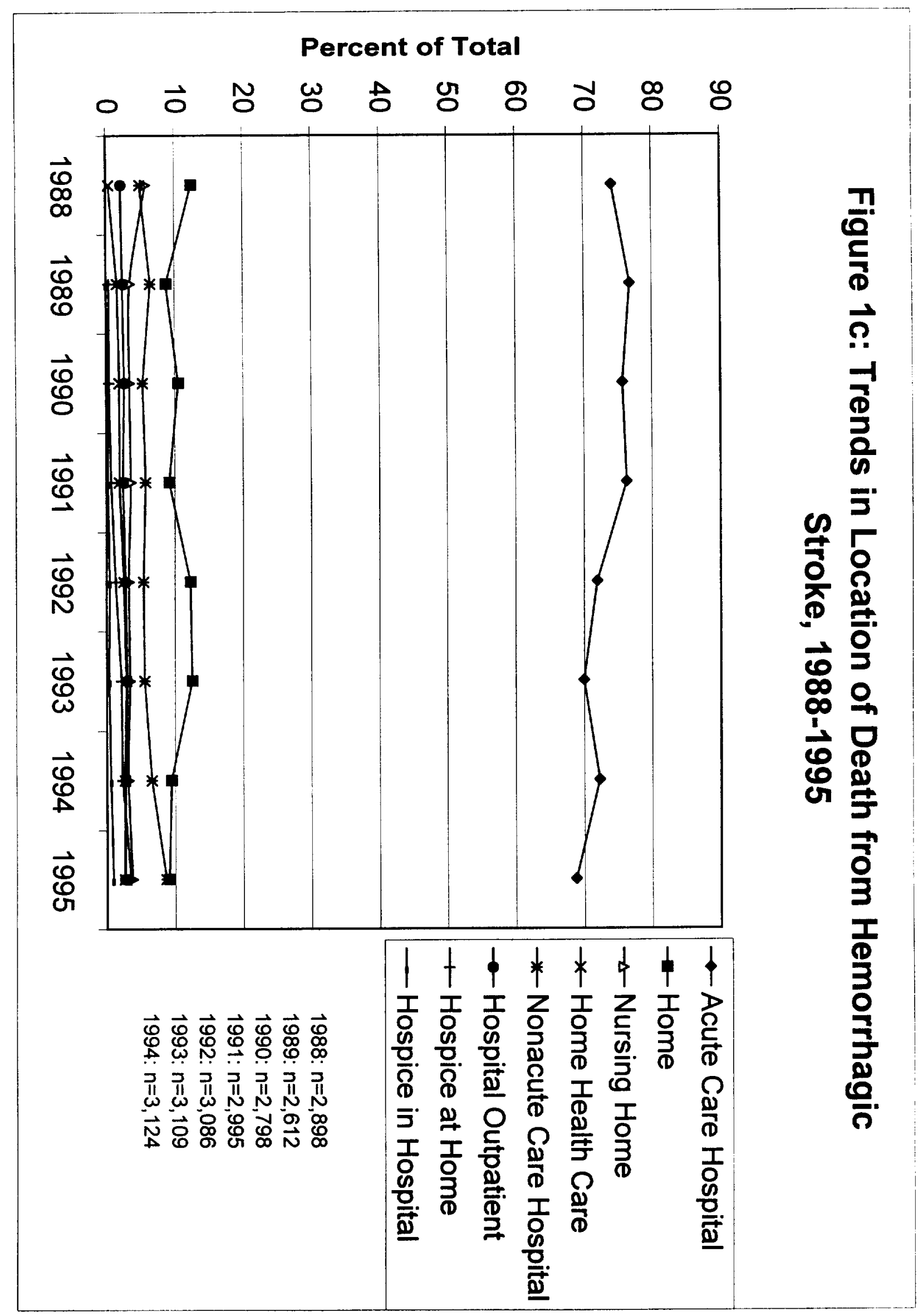




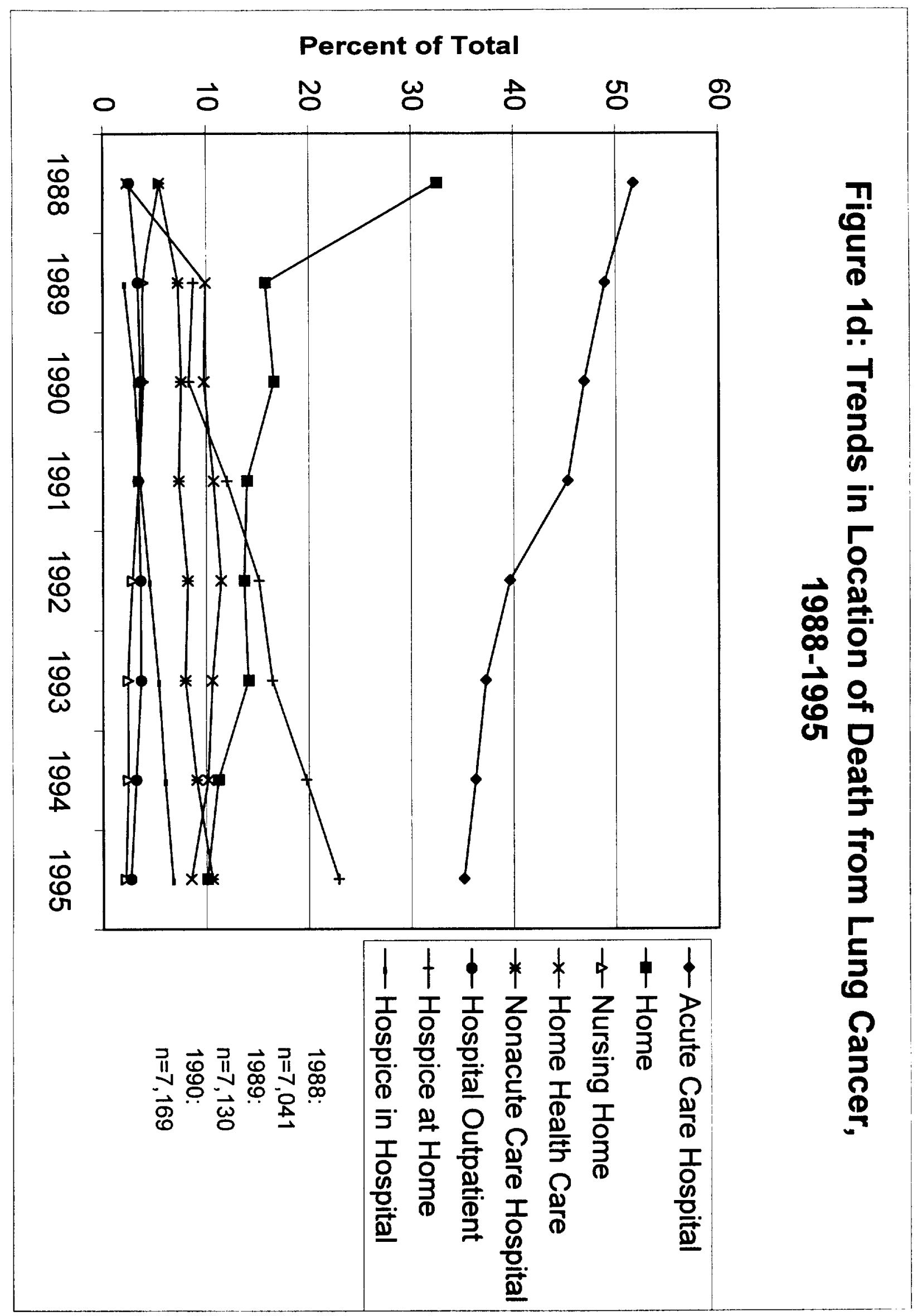




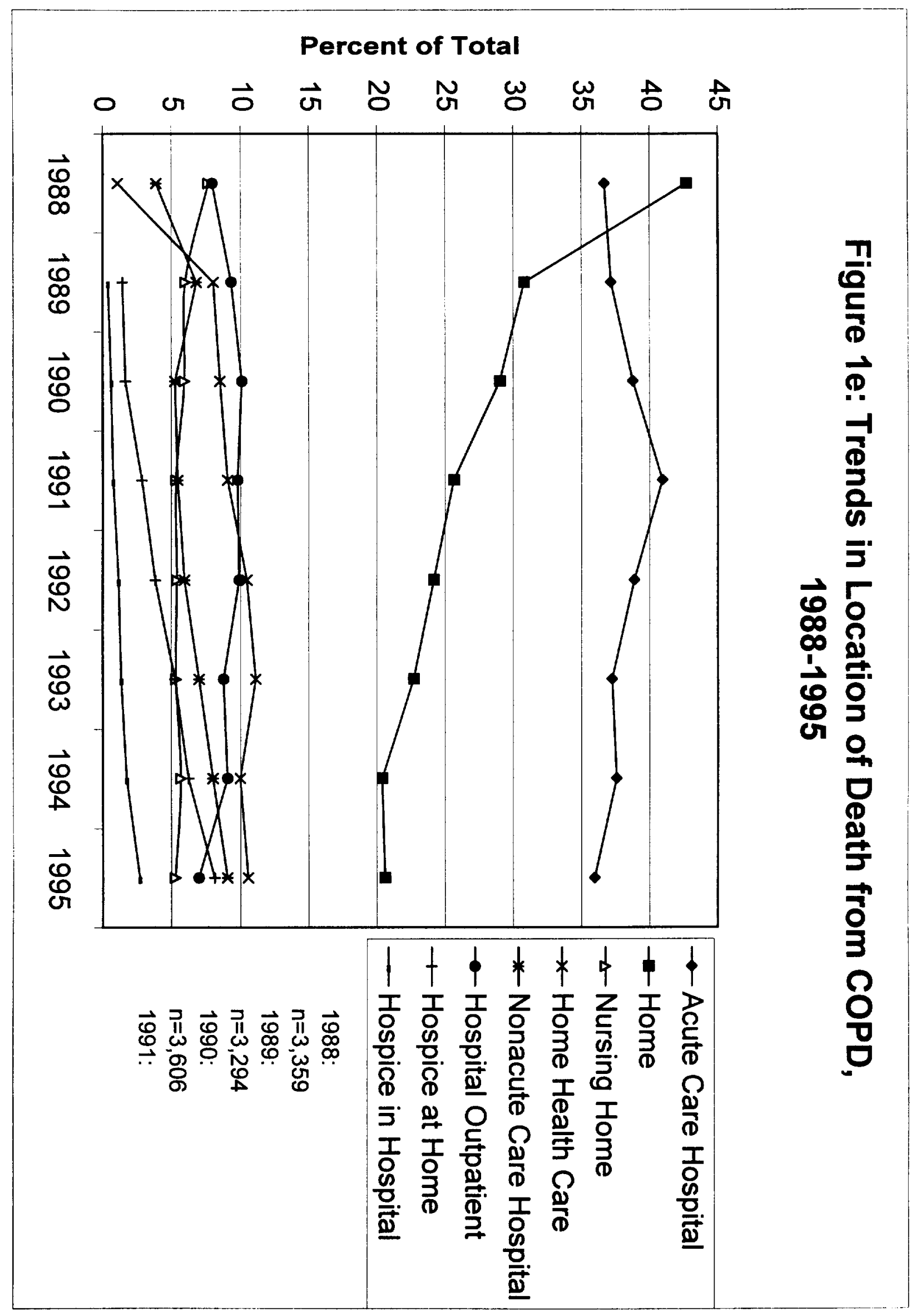




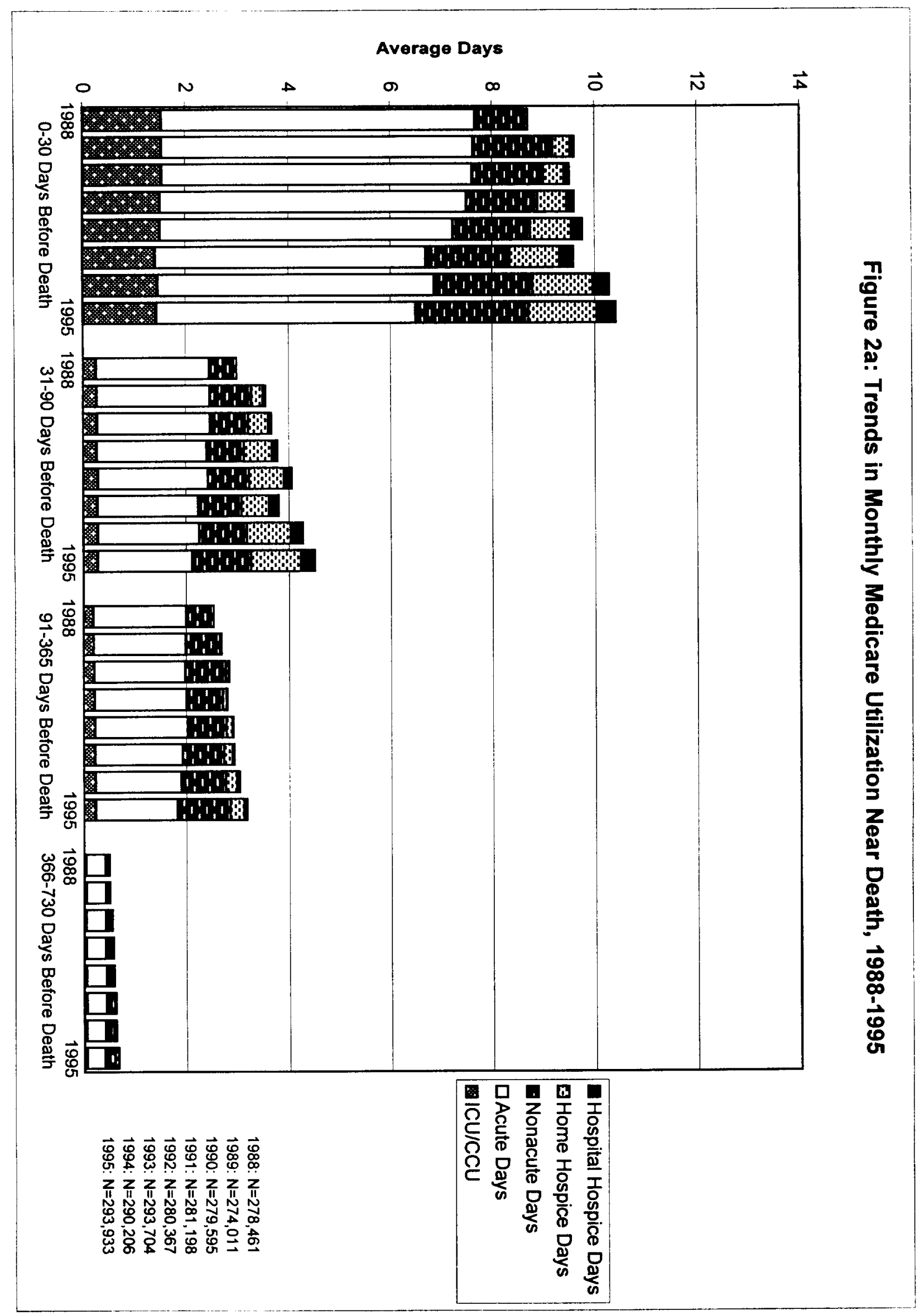




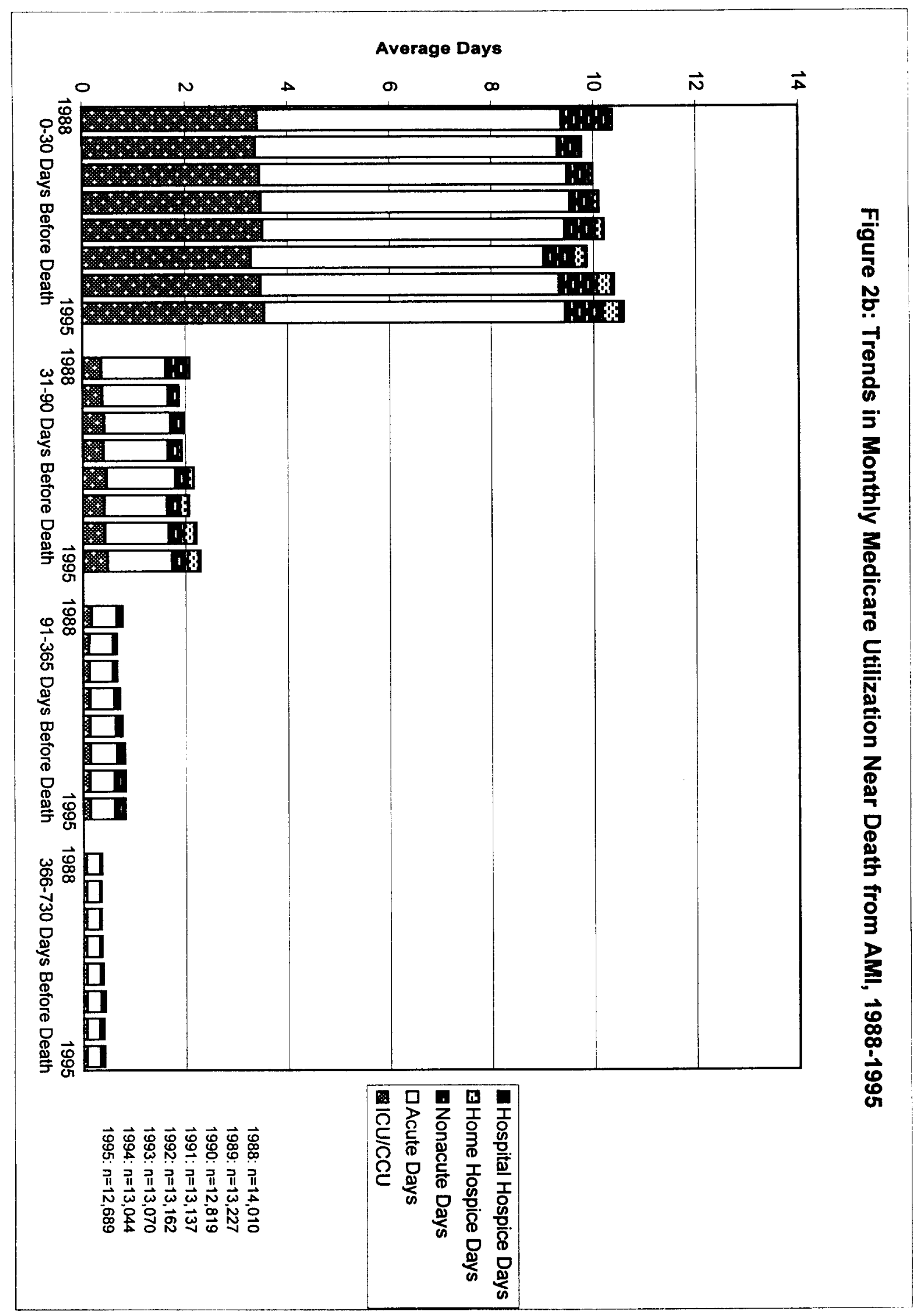




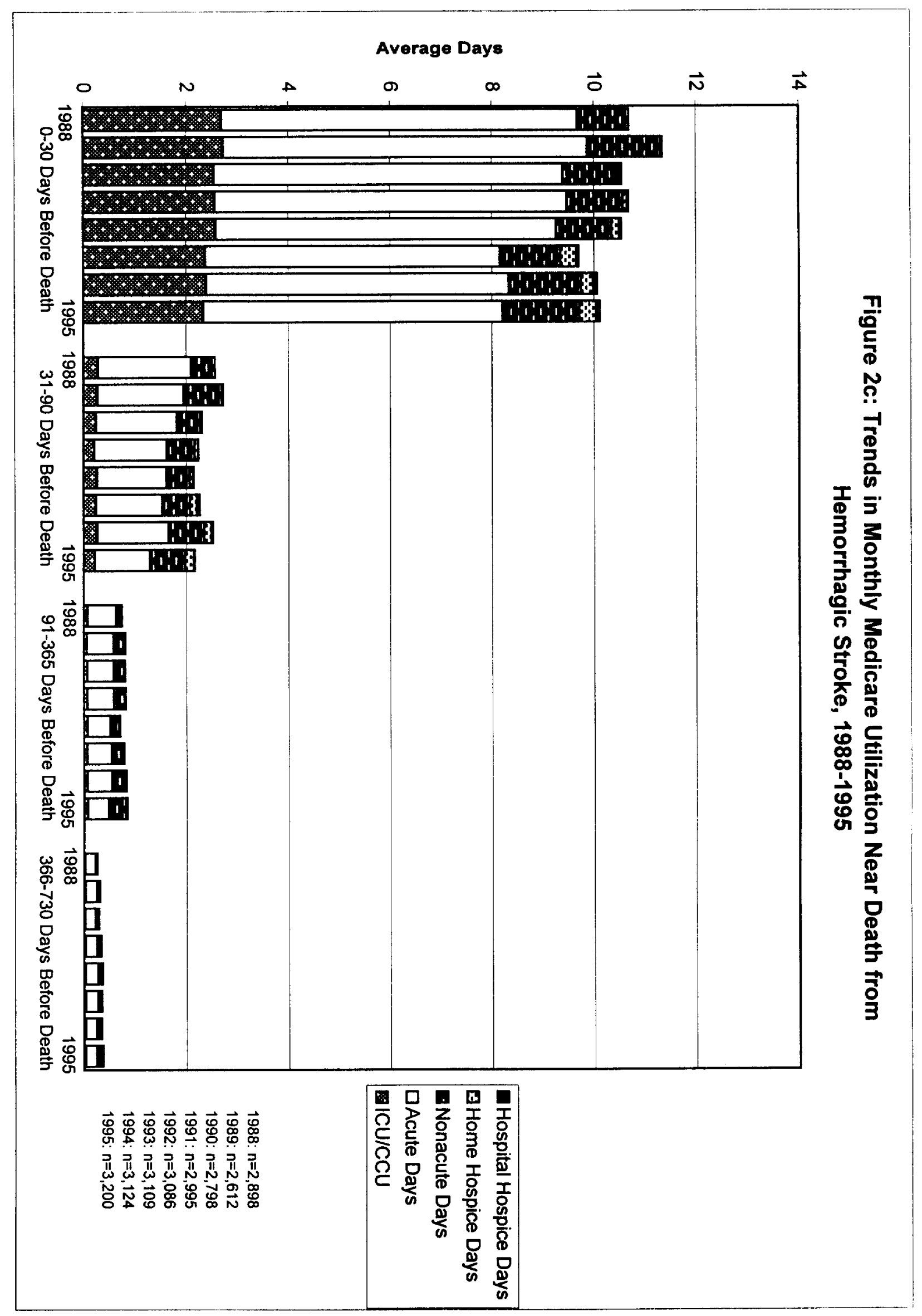




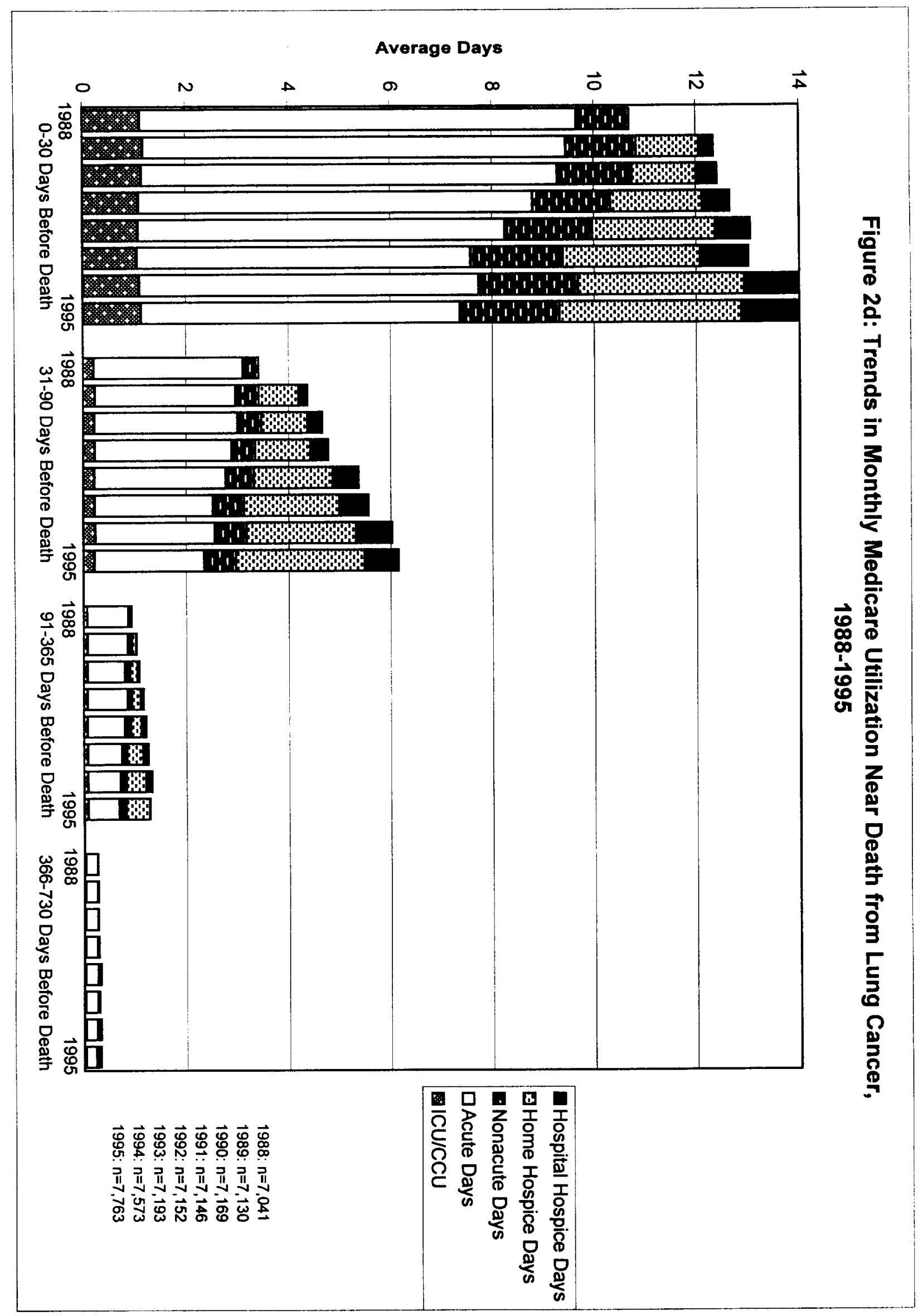




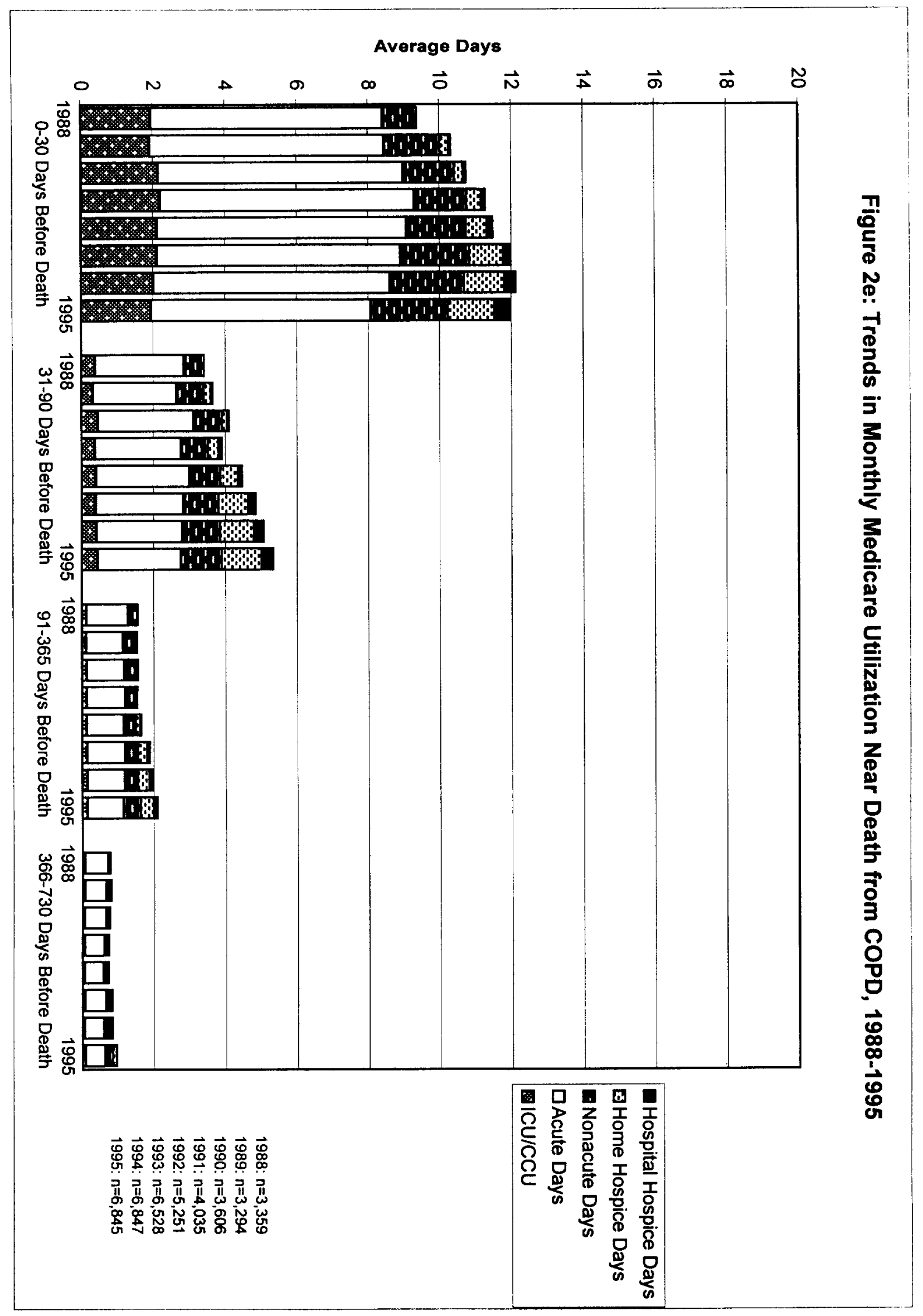




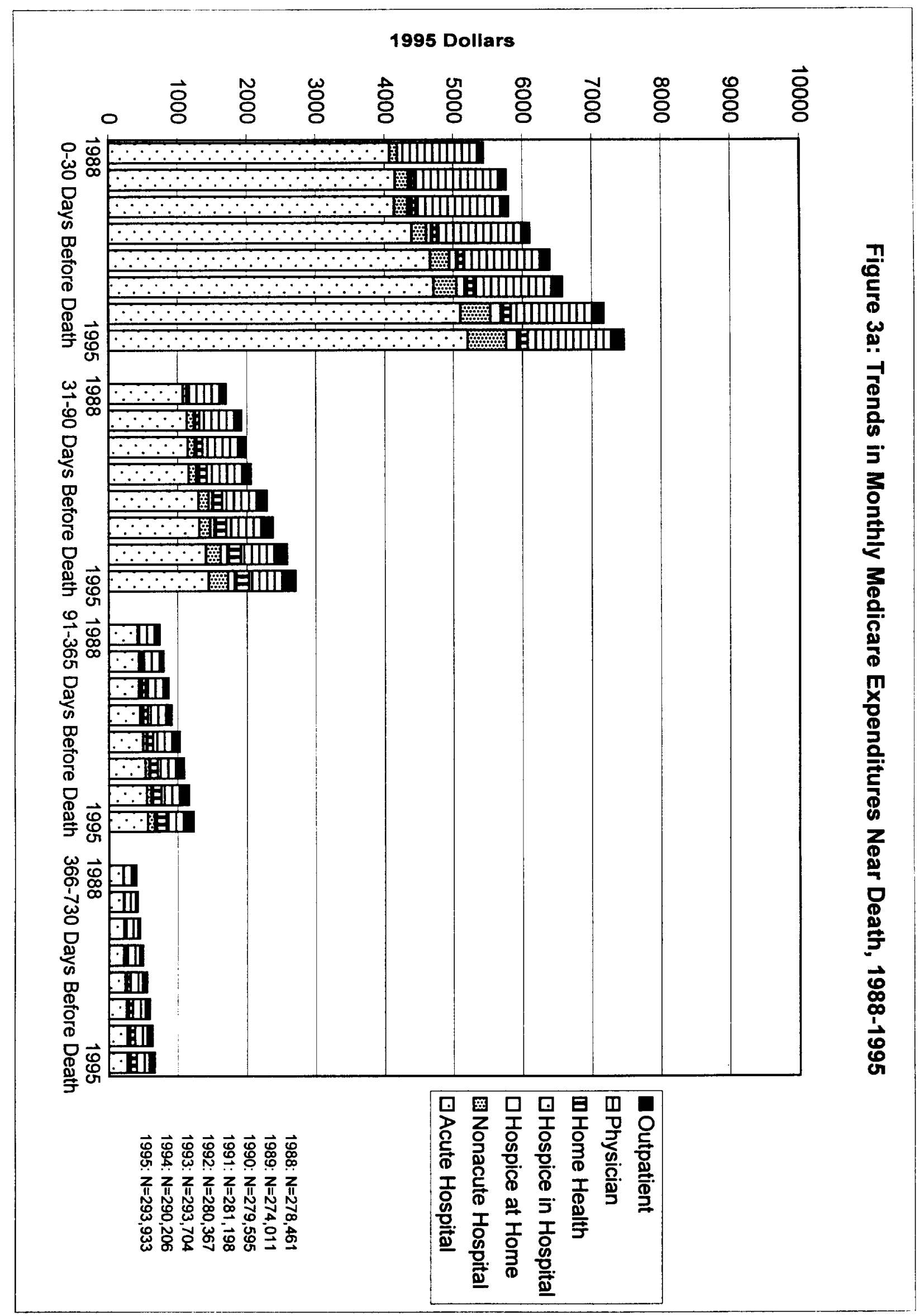




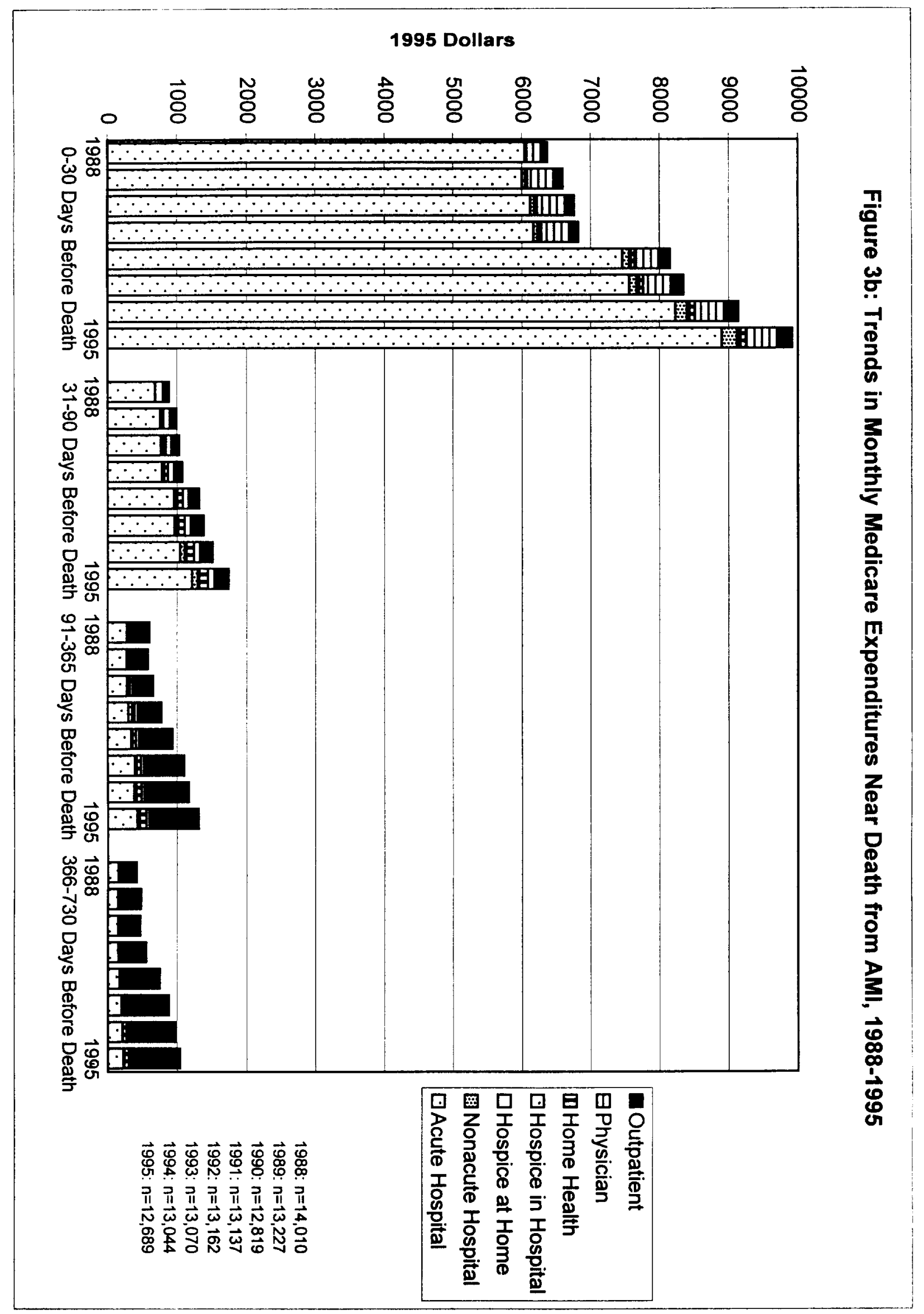




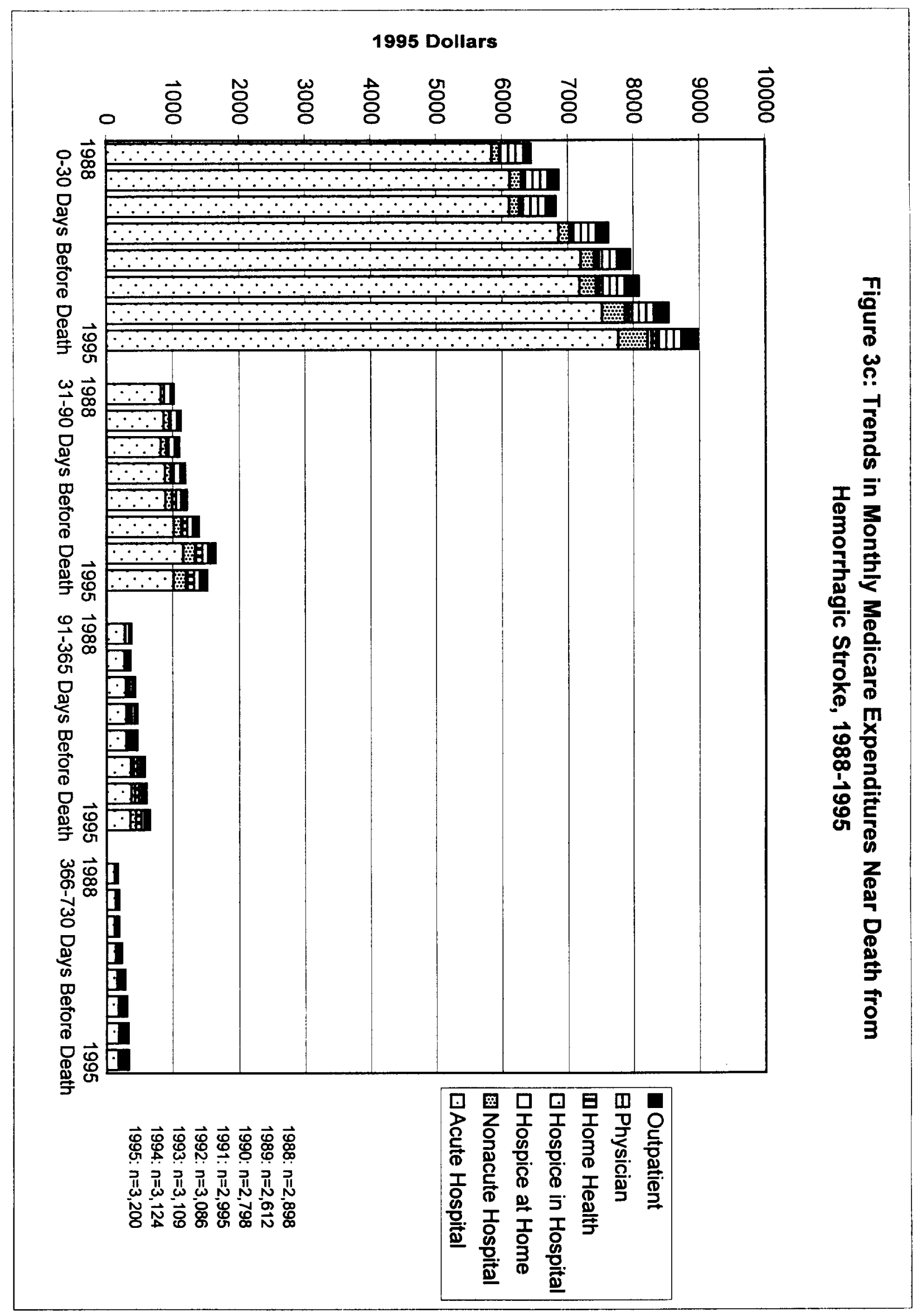




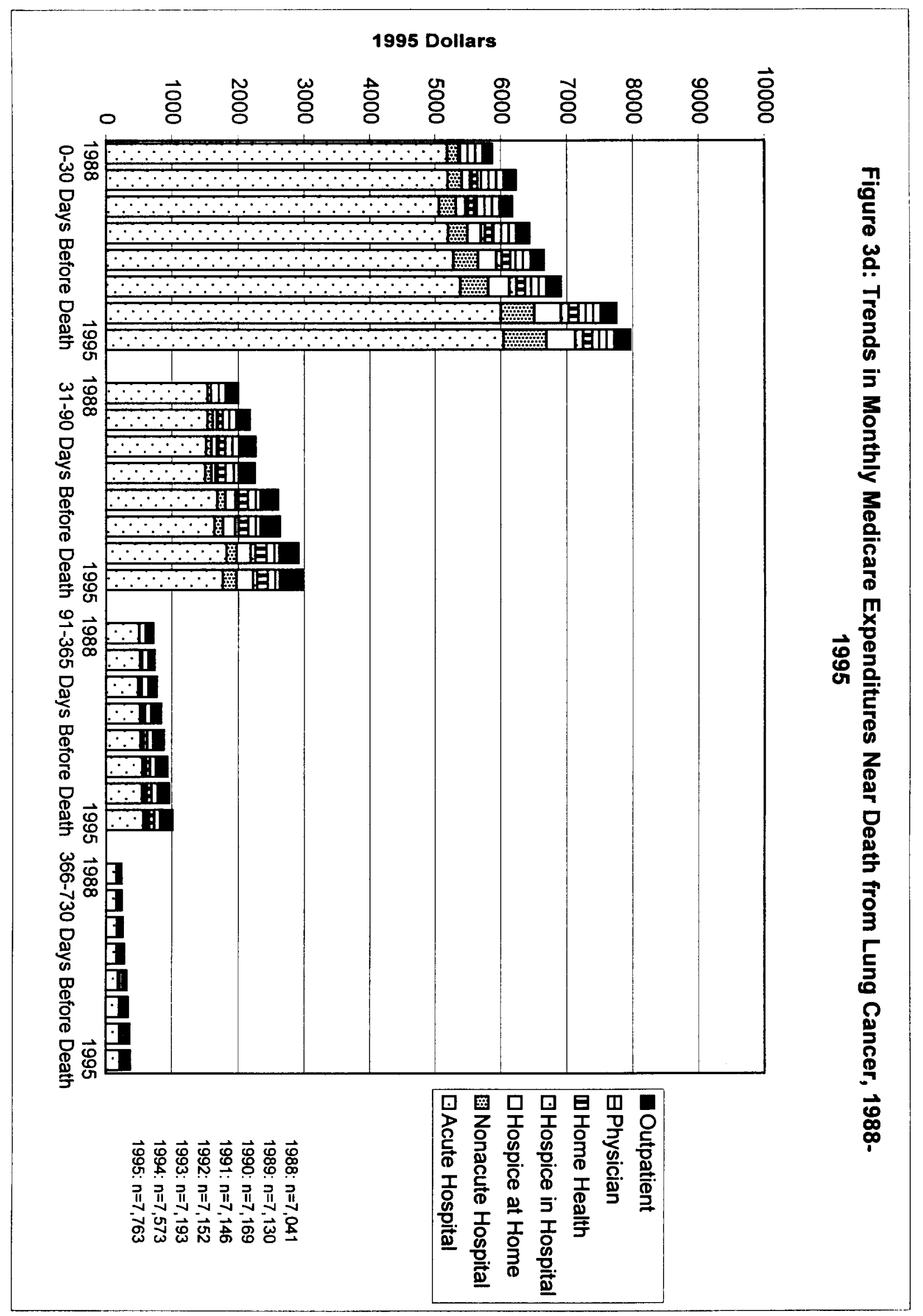




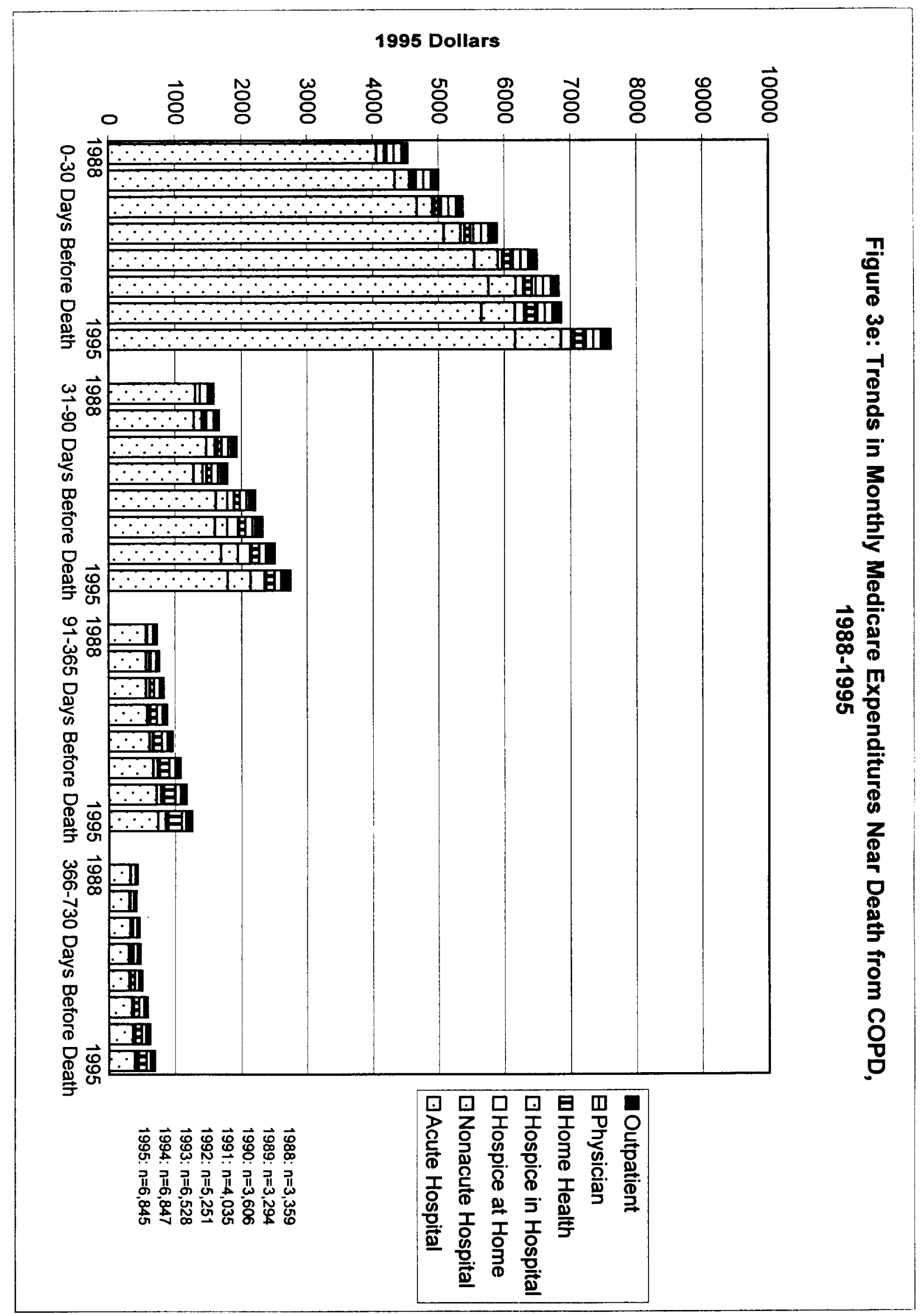




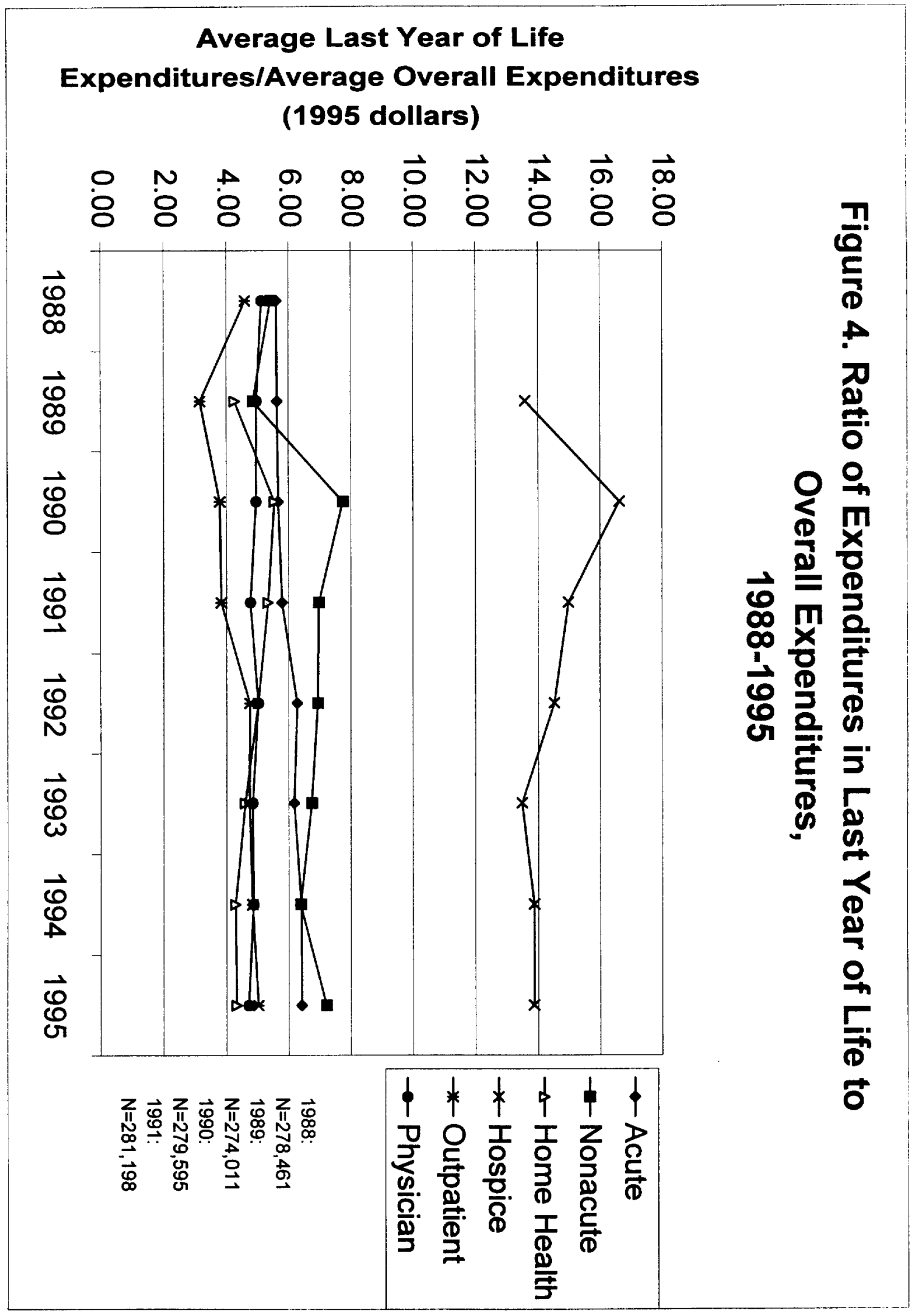

